\section{Evaluation of posturing in macular hole surgery}

\author{
D Verma ${ }^{1}$, MW Jalabi ${ }^{1}$, WG Watts ${ }^{2}$ and \\ G Naylor ${ }^{2}$
}

Abstract

Introduction

Aim To objectively evaluate the postoperative face down posturing in macular hole surgery.

Materials and Methods An electronic device called 'Maculog' was developed consisting of three basic components, a mercury switch triggered by the angle of tilt placed inside an earpiece, a data-recording device connected to the earpiece with cables and a windows based software program, specially written to analyse the recorded data in the form of tables and graphs. Ten patients undergoing macular hole surgery were fitted with the device on the first postoperative day before discharge. They were also asked for a subjective record of their posturing times. Four patients were given a posturing chair to take home. The device was retrieved after the first week and the data were downloaded to a PC for analysis. The actual posturing times recorded on the device were compared to the patients' own recollections.

Results In all ten patients the actual posturing time was less than the time they had recorded themselves. The average actual posturing time was $48 \%$ of the perceived posturing time. The worst time for posturing, as expected, was between midnight and early morning. The compliance was better in patients who used the posturing chair. Conclusions It is feasible to quantify the time of posturing using an electronic device and computer analysis. The study has shown that the actual posturing time is significantly less than the perceived posturing time. A further large study using 'Maculog' is now planned to correlate actual posturing time to the results of macular hole surgery.

Eye (2002) 16, 701-704. doi:10.1038/

sj.eye. 6700209

Keywords: macular hole surgery; posturing; pars plana vitrectomy; macula; vitreous; positioning
In the last 10 years, since Kelly and Wendel ${ }^{1}$ reported the pioneering study on vitreous surgery and injection of intraocular gas to close macular holes, this has become the most common indication for vitrectomy. Most surgeons use perfluoropropane $\left(\mathrm{C}_{3} \mathrm{~F}_{8}\right)$ or sulphur hexafluoride $\left(\mathrm{SF}_{6}\right)$ for prolonged internal tamponade advocating strict prone positioning (90-100\% of the time) for at least 1-2 weeks. Compliance with prone positioning very important factor in maximizing the chances of successful closure of macular holes. $^{2-4}$ Many of the elderly patients have cervical or lower back disease making prone positioning very difficult. ${ }^{5}$ Also greatest perioperative morbidity associated with macular hole surgery is most probably the strict postoperative face down positioning. ${ }^{6}$ In view of this some surgeons have adopted a no posturing regime and one such study reported a $79 \%$ surgical success rate though all the phakic eyes underwent simultaneous cataract extraction with intraocular lens implantation. ${ }^{7}$ Others have attempted to use silicone oil injection instead of gas to avoid strict posturing $^{8-10}$ but the technique has added risk of complications related to silicone oil and also requires second surgery for removal of oil. The role of posturing in macular hole surgery remains controversial. As far as we are aware, there are no means available to quantify actual posturing time other than patients' own recollection. This study is the first attempt in objective evaluation of posturing.

\section{Materials and methods}

An electronic device called 'Maculog' (Figure 1) was developed for the purpose of this study. The device consists of three basic components:

(1) A mercury switch triggered by the angle of tilt placed inside an earpiece. in the postoperative period is believed to be a
'Department of

Ophthalmology

Hull and East Yorkshire

NHS Trust

E Yorks, UK

2Department of Medical Physics

Hull and East Yorkshire

NHS Trust

E Yorks, UK

Correspondence:

D Verma MD FRCS

FRCOphth

Visiting Professor

Doheny Retina Institute

1450 San Pablo Street

DEI - 3611

Los Angeles

CA 90033-3699, USA

Tel: 323 442-6571

Fax: 323 442-6460

E-mail: dverma@

dei.hsc.usc.edu

Received: 26 July 2001

Accepted: 22 March 2002 


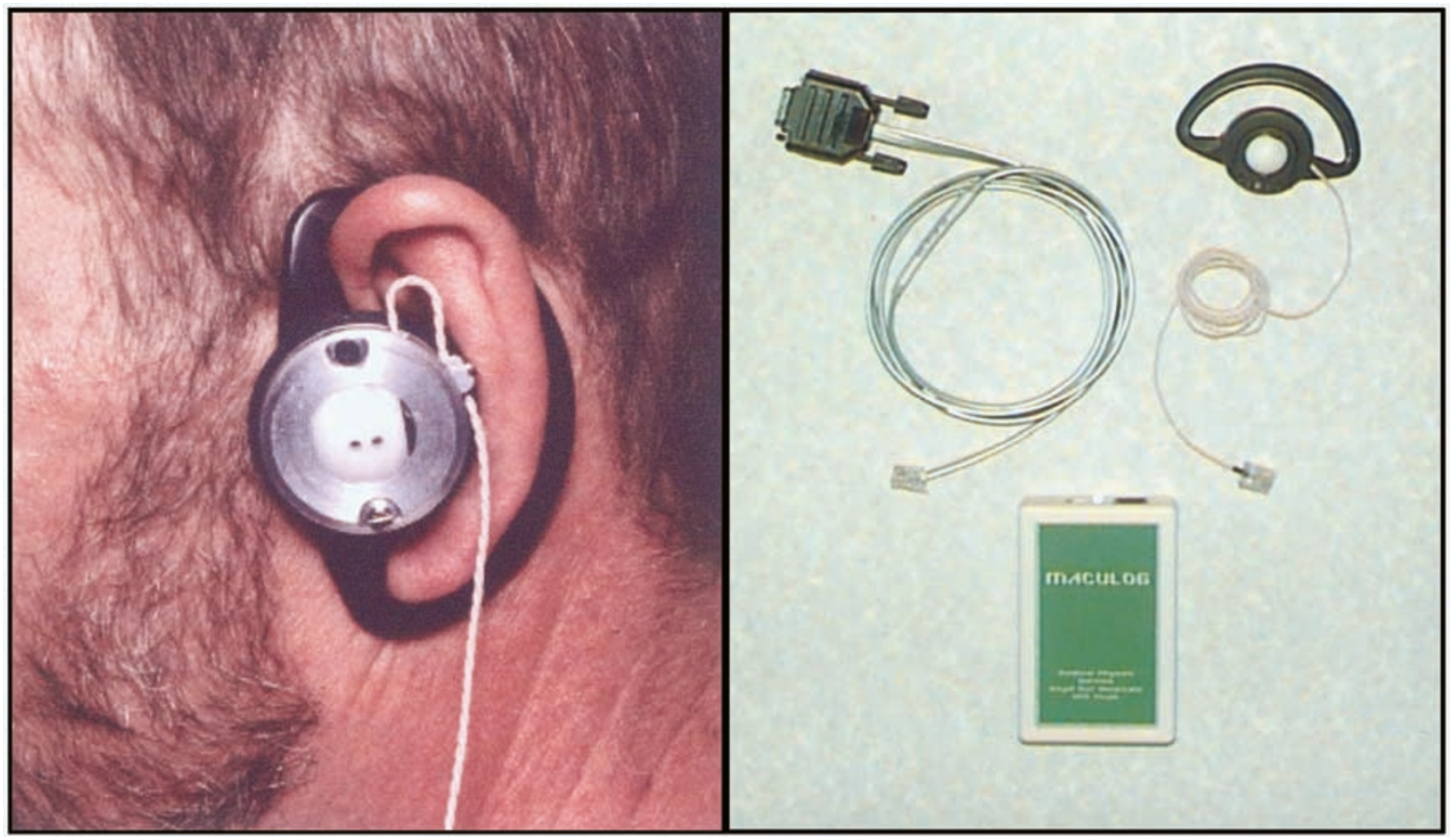

Figure 1 Components of 'Maculog' device with ear piece, data logger and connecting cables.

(2) A data-recording device connected to the earpiece with cables.

(3) A windows based computer programme specially written to analyse the recorded data in the form of tables and graphs.

The earpiece is shaped like a hearing aid incorporating a cut-out sphere with two holes for alignment tool. The mercury switch inside the sphere is connected to the wires that go into the data logger device. The switch is positioned to trigger a response when tilted $79^{\circ}$ on either side. The movement sensor is connected to the Micro-controller that in turn is connected to the Communication controller on one side and an address generator on the other. A real time clock is built in and the microprocessor has $1 \mathrm{MB}$ memory to record all the data. The communication controller can be connected to the host PC for downloading the data. Figure 2 explains the Data Logger circuitry in a schematic diagram.

The software specially written for 'Maculog' was downloaded on to a desktop Personal Computer (PC) in the ward. The program also included an 'anti cheating' mechanism to detect if the device was not used appropriately. This was achieved by incorporating a detector of the subtle movement of the box held at the waist or in the pocket of the patient. These movements would disappear if the patient were to take the device off and place it on a table in the right posture.

Eight female and two male patients undergoing macular hole surgery were recruited for this study.
Age ranged from 66 to 85 yrs. Informed consent was obtained after explaining the nature of the study in detail. The only inclusion criterion was the suitability of a patient for macular hole surgery. The indications for surgery, preoperative counselling and postoperative strict posturing instructions were followed as per standard practice at that time. Since this study was designed only to assess the ability of patients to posture, there were no exclusion criteria. Pars plana vitrectomy with fluid gas exchange using $14 \% \mathrm{C}_{3} \mathrm{~F}_{8}$ was carried out under general anaesthesia.

Autologus serum was used as an adjunct in all cases. Nursing instructions for the first postoperative night were to keep the patient in supine position as much as possible. Postoperative dressing was carried out on the next morning and the instructions for strict 'head down' posturing regime were reinforced. Four patients in the study were also given a posturing chair to take home for the first week.

Patients were asked to record their own perceived posturing times for the first postoperative week. Prior to discharge from the ward, the device was fitted on the patients' ear lobe (Figure 1) and cables were connected to the recording box, attached to the waist. Patients were instructed to keep this in place all the time and to return it on their first visit to the outpatients department after one week. The data were then downloaded to the desktop PC in the ward with the special software for analysis. The actual posturing times recorded on the device were compared to the patients' own recollection. 


\section{Schematic of Data Logger circuit}

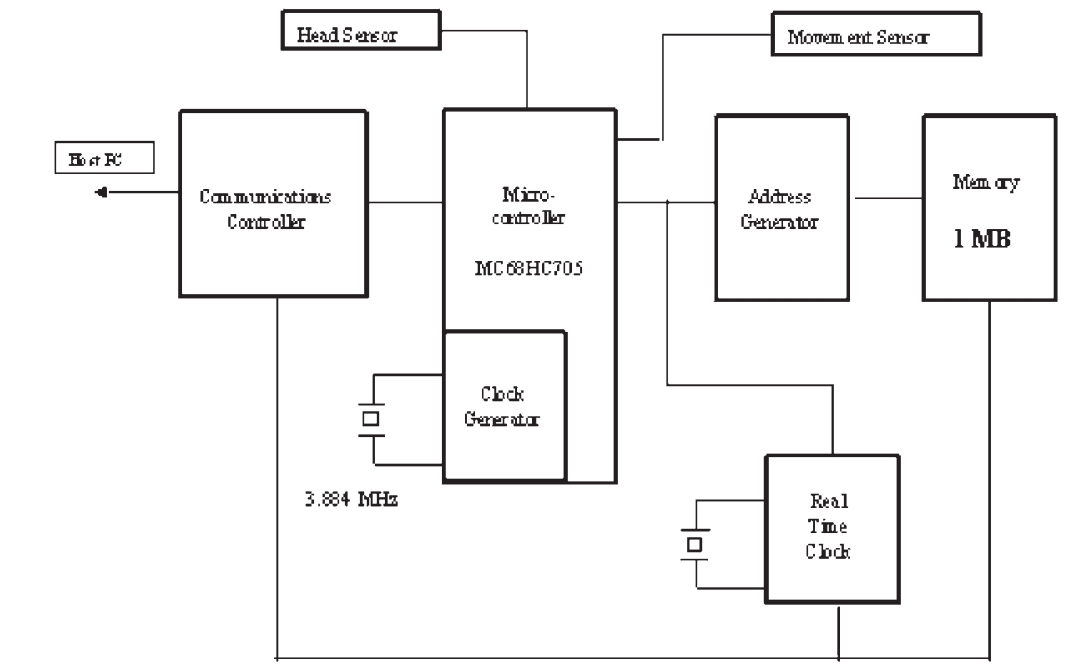

Figure 2 Data logger circuit.

\section{Results}

Results of the posturing times recorded on the device were tabulated for each patient and analysed using the software developed for the purpose. Each recording was also depicted in graphic form (Figure 3). None of the patients tried to influence the results by placing the device on the table, as the 'anti-cheating' mechanism demonstrated some movement of the box at all times. The actual posturing time ranged from $27 \%$ to $79 \%$ with an average of only $38 \%$ of the whole time. Patient's own recollection of their posturing time ranged from $58 \%$ to $90 \%$. In all ten patients the actual posturing time recorded by the device was less than the time they had recorded themselves. The average actual posturing time was $48 \%$ of the perceived posturing time. The worst time for posturing, as expected, was between midnight and early morning. The actual posturing time was on average $12 \%$ higher in all four patients who used the posturing chair but the numbers were too small for any statistical significance.

\section{Discussion}

Compliance with strict prone positioning in the postoperative period is believed to be an important factor in success of macular hole surgery by most surgeons. Great emphasis is placed on the ability of patients to follow the strict face-down posturing regimes even before macular hole surgery is considered. ${ }^{4}$ Previous studies have shown some evidence that duration of posturing or percentage of expansile gas used may have some influence on the results. ${ }^{2,3,5}$ On the other hand greatest perioperative morbidity associated with macular hole surgery is also believed to be due to strict posturing. ${ }^{6}$ Attempts at no posturing surgery ${ }^{7}$ or use of silicone oil tamponade $\mathrm{e}^{8-10}$ have lower success rate and/or additional risks. The role of posturing in macular hole surgery remains controversial. As far as we are aware this study presents the first attempt to objectively evaluate the time of postoperative posturing by patients undergoing macular hole surgery. A simple electronic device incorporating a mercury switch that triggers a signal sensitive to the angle of head tilt, enables the actual time of posturing to be recorded and analysed later. The results in this small group of patients have shown that they were really able to posture less than half of the time they thought they were posturing. This brings forth the question of compliance on the part of this elderly age group who usually have many systemic problems and arthritic joints. Based on these initial results showing poor compliance, the next obvious question that arises is whether posturing is really that critical for the success of macular hole surgery? We feel that the device 'Maculog' may be able to help us design a much larger study to correlate the results of macular hole surgery to duration of posturing in the 


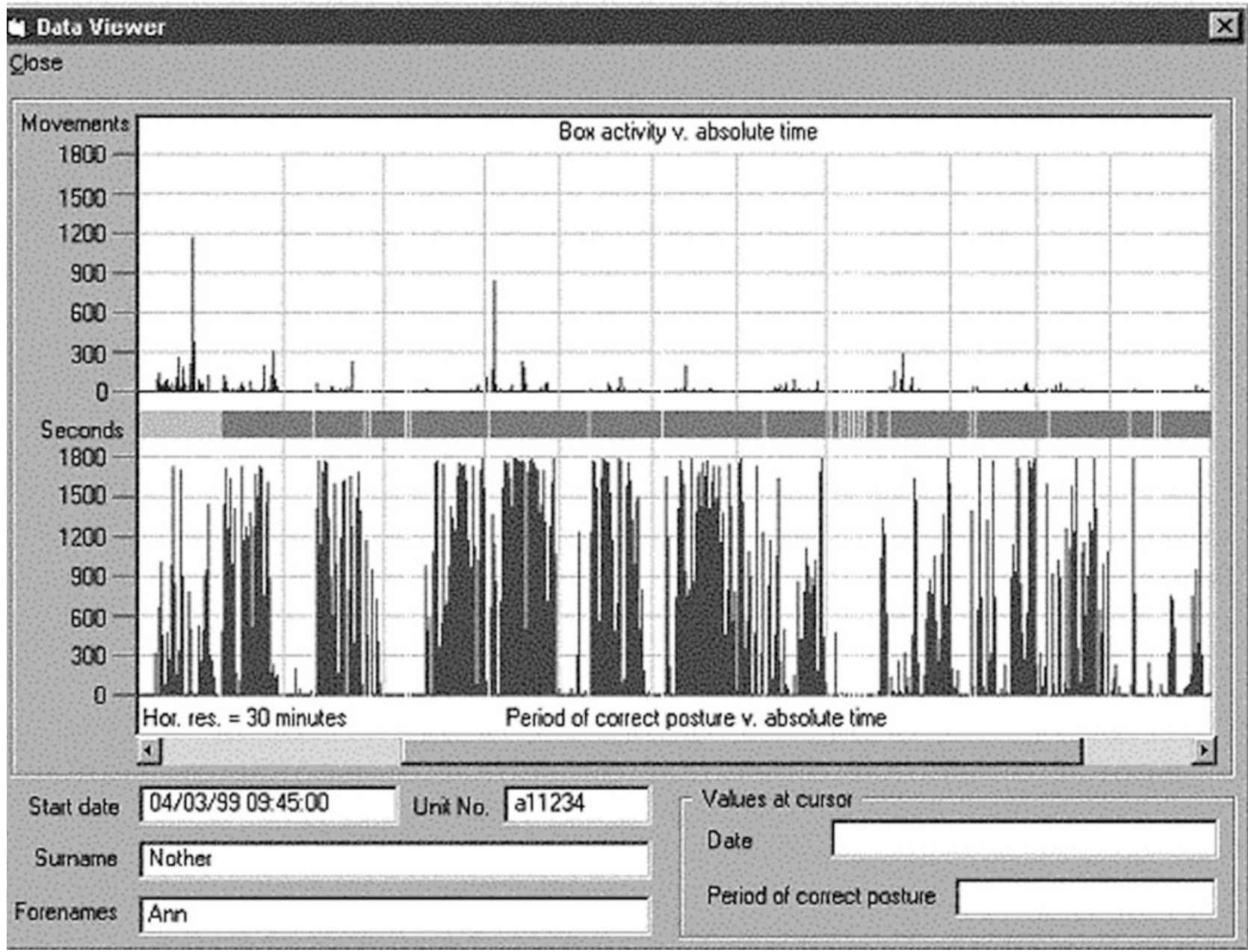

Figure 3 Visual record of posturing times on data viewer.

near future. Other future uses of this device may be to improve posturing for patients by incorporating an audible alarm system that could be triggered if the patients were not in the right posture. We are planning these further modifications and larger studies to answer these questions.

\section{Acknowledgements}

Part of this study was presented as a poster at the annual congress of Royal College of Ophthalmologists held at Harrogate in 2000.

The authors have submitted an application for patent for the device 'Maculog' and its future modifications.

\section{References}

1 Kelly NE, Wendel RT. Vitreous surgery for idiopathic macular holes. Results of a pilot study. Arch Ophthalmol 1991; 109: 654-659.

2 Wendel RT, Patel AC, Kelly NE et al. Vitreous surgery for macular holes. Ophthalmology 1993; 100: 1671-1676.
3 Thompson JT, Glaser BM, Sjaarda RN, Murphy RP, Hanham A. Effects of intraocular bubble duration in the treatment of macular holes by vitrectomy and transforming growth factor-beta2. Ophthalmology 1994; 101: 1195-1200.

4 Thompson JT, Smiddy WE, Glaser BM, Sjaarda RN, Flynn HW Jr. Intraocular tamponde duration and success of macular hole surgery. Retina 1996; 16: 373-382.

5 Cullen R. Macular hole surgery: helpful tips for preoperative planning and postoperative face-down positioning. J Ophthalmic Nurs Technol 1998; 17: 179-181.

6 Sjaarda RN, Thomson JT. Macular hole. In: Ryan SJ, Wilkinson CP (eds). Retina, 3rd edn, Vol 3. Mosby: St Louis, 2001, pp 2547-2561.

7 Tornambe PE, Poliner LS, Grote KD. Macular hole surgery without facedown positioning: a pilot study. Retina 1997; 17: 179-185.

8 Goldbaum MH, McCuen BW, Hanneken AM, Burgess SK, Chen HH. Silicone oil tamponade to seal macular holes without position restrictions. Ophthalmology 1998; 105: 2140-2147.

9 Pertile G, Claes C. Silicone oil vs gas for the treatment of full-thickness macular hole. Bull Soc Belge Ophtalmol 1999; 274: 31-36.

10 Lam DS, Chan WM, Tam BS. Silicone oil tamponade for macular holes. Ophthalmology 2000; 107: 1. 